\title{
The Punctual Bufflehead, Bucephala albeola: Autumn Arrivals in Shoal Harbour Sanctuary, Vancouver Island, in Relation to Freeze-up
}

\author{
JAMES K. FINLEY \\ 10232 Summerset Place, Sidney, British Columbia V8L 4X2 Canada
}

Finley, James K. 2007. The punctual Bufflehead, Bucephala albeola: Autumn arrivals in Shoal Harbour Sanctuary, Vancouver Island, in relation to freeze-up. Canadian Field-Naturalist 121(4): 370-374.

Buffleheads are punctual in their return to wintering grounds on the Pacific coast. First arrivals appeared in Shoal Harbour Migratory Bird Sanctuary, southeastern Vancouver Island, on the $288^{\text {th }}$ day of the year on average $( \pm$ S.D. $2.3 ; n=10)$, that is, 15 October. This vanguard preceded the first peak influx by about 15-20 days, and a second influx by about 24-26 days. First arrivals usually appeared by mid-morning, and included singles (females on two occasions) and small flocks of up to eight. First arrivals may represent a photoperiodic threshold, whereas subsequent peak influxes represent climatic thresholds associated with freeze-up. The phenology of Bufflehead autumn migrations is a good proxy indicator of the advance of the zero degree isotherm, and thus of climatic variability. The timing of their autumn migrations does not appear to have changed in the last half of the twentieth century, consistent with evidence that freeze-up has not advanced. Monitoring of their migrations, in conjunction with shore-based observations of freeze-up, would validate one-dimensional thermodynamic models of freeze-up, and provide a more ecologically meaningful index of climate change, at minimal cost.

Key Words: Bufflehead, Bucephala albeola, phenological precision, autumn arrivals, freeze-up, climate change.

Synchronicity of life cycles with environmental cues is a key determinant of fitness, survivorship and reproductive success. With growing public interest in the impacts of global warming, there has been a resurgence in documenting phenological phenomema as indicators of environmental change. In Britain, for example, the average arrival dates of twenty migrants have advanced by eight days in the last several decades, raising concern that asynchrony in biological cycles with climatic change will increase stress on species, particularly the specialists (Cotton 2003).

The Bufflehead is a specialist, occupying a narrow niche, and is remarkable amongst the seaducks in that its population has remained stable over decades (Gauthier 1993). In his monograph on the species, Erskine (1972), advised that "If you would become familiar with a bird, you must live with it, day by day through the seasons, following the activities that fill its life and add up to the picture conjured up by its name. So it is with the bufflehead. ... People fortunate enough to live on the water's edge may watch buffleheads from their breakfast table ...". I'm one of the fortunate ones, being able to observe Buffleheads from my breakfast table, overlooking Shoal Harbour Migratory Bird Sanctuary, Vancouver Island, since 1984.

I've long been fascinated by the strange circumstances and climatic events that caused the "Great Bufflehead Crash" on the night of 4 November 1940 in eastern Saskatchewan (Swallow 1941; Erskine 1972; Finley 2001), and I wait their arrival eagerly, as I simultaneously watch satellite images of anti-cyclonic systems breaking over the mountains. Here, I document the timing of their autumn arrival during the last decade, and attempt to relate this to the latest research in freezeup phenology and climate change.

\section{Methods}

My bay-window observatory, situated in Sidney, British Columbia, overlooks Roberts Bay, part of Shoal Harbour Migratory Bird Sanctuary, southeastern Vancouver Island, one of the oldest marine migratory bird sanctuaries on the Pacific coast, established in 1931 (Dawe 1982). Between 1996 and 2005, I kept watch daily for first arrivals in September and October. At least once every morning and at the end of the day during October, I scanned the bay with the aid of binoculars or telescope. In practice, the bay was under observation semi-continuously from either my kitchen window or my study window; however, due to the routines of family life, first scans usually took place between 8:30 to 9:00 $\mathrm{h}$ and last scans between 16:00 and dusk. Observations on behaviour, numbers and sex composition were entered in a daily diary, and later transferred to a computer spreadsheet. In most years between 2000 and 2006, total numbers were recorded daily until mid-November. Periods when numbers increased abruptly by more than $30 \%$ on two consecutive days were considered as peak influxes.

\section{Results}

First arrivals appeared around the $288^{\text {th }}$ day $( \pm$ S.D. $2.3 ; n=10$; i.e., 15 October) of the Julian calendar (Table 1). They included singles on three occasions and flock sizes up to eight. Singles included "females" in two cases; drakes were always amongst the first arrivals, accounting for 14 of 38 (37\%) of them. Most 


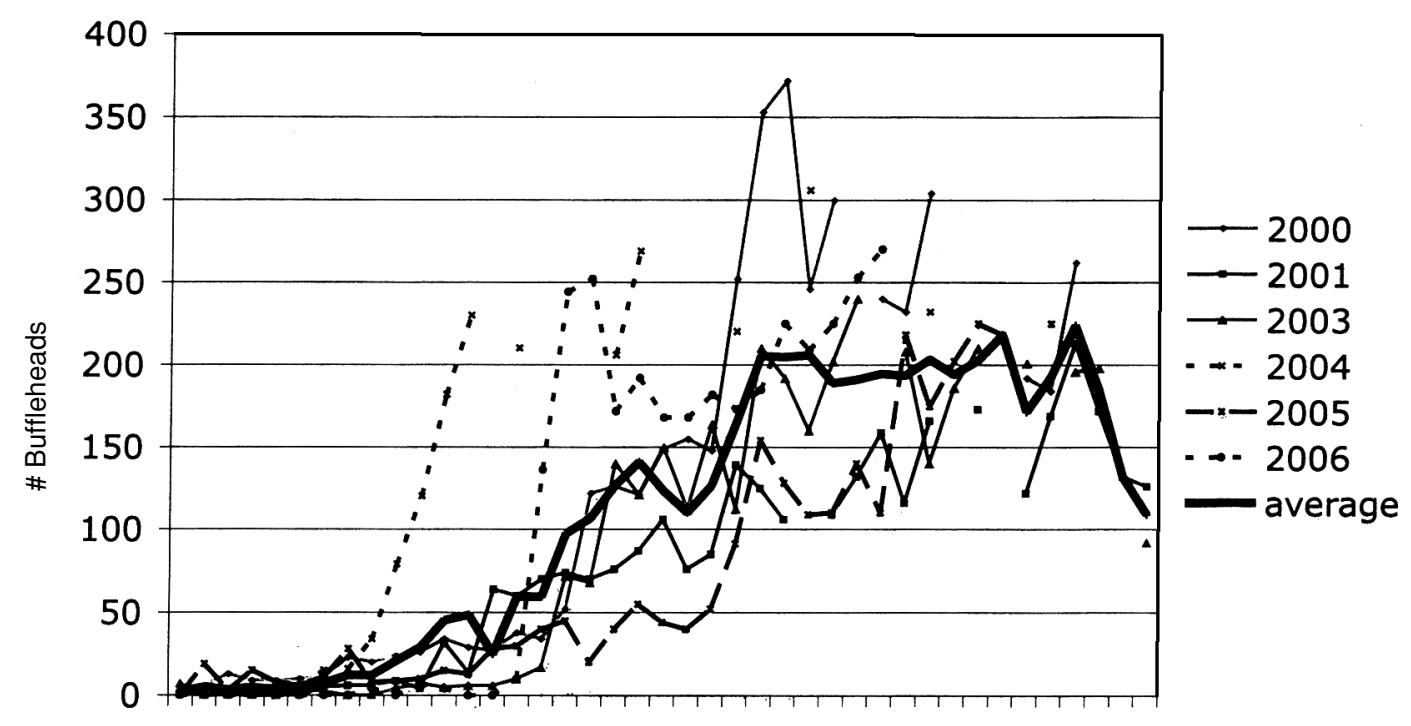

FIGURE 1. Buffehead phenology: autumn numbers of Buffleheads on Roberts Bay, Shoal Harbour Migratory Bird Sanctuary, mid-October to late November, in various years between 2000 and 2006.

arrivals appeared by 09:00, and they always appeared in the same general location (radius about $150 \mathrm{~m}$ ), around the delta of an estuarine creek. Numbers until late October remained small, averaging less than 6\% of peak numbers. First arrivals preceded the first peak influx by about 15 to 20 days (typically the end of October), and a second influx by about 24-26 days (7-9 November), though the first peak was sometimes not evident, e.g., 2001 and 2005 (Figure 1). The percentage of males on various days varied considerably, averaging 42 percent $(n=38)$, with no apparent trend during the influx period.

\section{Discussion}

Due to their high albedo and activity, male Buffleheads are difficult to overlook, and because Roberts Bay is just the right size, I'm confident that the data presented here are reliable. Their timing, first thing in the morning, indicates their propensity for nocturnal navigation. Though the precise timing is biased by my morning schedule, it is evident that they arrive sometime after dawn, conveniently around breakfast time, as enviously noted by Erskine (1972). On several occasions, it was apparent that they had just touched down, and on one occasion, 15 October 2003 ("AllBuffleheads Day"), I saw them fly in and land. First arrivals were often flighty, sometimes disappearing and returning during the day, or disappearing for several days, but most took up residence and courtship right away.

Throughout October and into November, new arrivals remain mostly in the core area where they initially landed, and intense courtship takes place before birds take up their feeding territories. This initial touch-down zone is a central arena in Bufflehead society, to which known individuals of monogamous pairs return year after year (Finley, unpublished). Such philopatry, or "home-loving" behaviour, is a genetic trait passed on over generations, providing a survival advantage through intimate knowledge of their environs, culturally transmitted through the wisdom of successful mature individuals. Thus, philopatric Buffleheads are "homing in" on their tribal territories, and they do so, in a punctual manner.

Buffleheads show a high degree of synchronicity and phenological precision in their life cycle, hatching out in latitude $52^{\circ} \mathrm{N}$ on Julian day $169.5 \pm$ SE 1.6 (18 June; Evans et al. 2002) and, about 119 days later, arriving on their wintering grounds, in latitude $48^{\circ} \mathrm{N}$. These life events, synchronized with the solar cycle, represent significant seasonal demarcations in the calendar of temperate boreal, aspen-parkland ecosystems. Not only do Buffleheads show punctuality by their solar calendar, but they also synchronize their 
daily life precisely with light levels (Finley 2007). They are an exemplary model of precision and punctuality, daily and seasonally.

Erskine (1972: 128) noted that "Reported first arrivals are often single birds moving a month or even more before migration gets under way in earnest." Erskine also reported that only isolated individuals appeared before 10 October. He illustrated the isolines of migration fronts in 1962 over North America, although the entire coast of British Columbia fell into a zone of uncertainty between 11 and 21 October. Using published records and questionnaires, Erskine calculated arrival dates over the twentieth century for various locations on Vancouver Island and Puget Sound, Washington, noting that "few observers are in a position to observe bufflehead habitat daily or even weekly, and many first dates represent only the time of first visit to a particular area". Still, he found the averages were remarkably uniform around 18 October (S.D. \pm 2 around five regional means, based on 45 records) for five locations on Vancouver Island between 1903 and 1962. Victoria averaged 18 October based on eight years between 1955-1962. If anything, the potential bias by discontinuous observation would be toward a later date as suggested by this study. Or, as Erskine has suggested (personal communication, 2008), first arrivals might appear slightly earlier in prime habitat like Roberts Bay, rather than in adjacent areas.

Erskine (1972) estimated that the first general movement from the breeding grounds began around $20 \mathrm{Oc}-$ tober, and observed that peak migration across the continent was highly concentrated during the first week of November, noting the concurrence of this movement with the "Great Bufflehead Crash" on 4 November 1940 (Swallow 1941; Finley 2001). Bellrose (1976) remarked that this first wave of migration occurred at "surprisingly similar times" across the northern plains. Erskine (1972) believed that migration peaks were correlated with mean temperatures and the timing of freeze-up, and - lacking the instantaneous advantage we have today of viewing the earth on-line - he illustrated the general weather system that forced mass movements of Buffleheads out of their breeding grounds. An example of this system, the first sustained high pressure system in the Mackenzie Basin, is illustrated by Woo et al. (2007). Because the thermodynamics of freeze-up are a good integrative measure of climate (Menard et al. 2002; Jefferies 2005), the phenology of Bufflehead autumn migrations should be a good proxy indicator of the advance of the zero degree isotherm, and thus of climatic variability.

Buffleheads presumably respond to seasonal changes in light levels, mediated by the pineal gland, such that light levels induce "zugunruhe", or migratory restlessness (Welty 1975). They arrive here two or three days after the average date of freeze-up of their most northerly breeding grounds in central Alaska (Jefferies et al. 2005). Thus, the onset of migration may represent a threshold effect of the mid-October photoperiod, whereas the first major influx in late October may represent a thermodynamic threshold associated with general freeze-up, a reliable indicator of the first significant outflow of arctic air, and the advance of the zero degree isotherm. The exact timing of the first influx is determined by weather patterns and the need for clear nights for celestial navigation, conditions typical of high-pressure air masses, in the aftermath of a front. The earliest influx, beginning 23 October 2004, corresponded to the first snowfall on the prairies. The rapid increase to peak numbers on 30 October 2006 was due to a major incursion of arctic air and a rapid freeze-up throughout the west, whereas the delayed build-up in 2005 was due to warmer than normal conditions, and late freeze-up (Environment Canada 2006*). The first influx was not always marked (e.g., 2001 and 2005), but the last one tends to occur just before Remembrance Day (11 November) and may represent the climatic domain and freeze-up phenology of the interior of British Columbia, and/or the arrival of a different component of the population.

I did not monitor numbers continuously in 2007 but did note influxes on 27 October and 11 November, the latter preceding the first major storm front of what was to become La Nina's infamous winter from hell. This latter influx included a distinctive female of a pair that has returned annually to the same territory for the past three years, so it may be that the breeding pairs are amongst the last to arrive, having re-joined in the interior before their overnight flight. Lack of any clear trend in the male composition of flocks suggests that re-integration of the sexes and pair re-bonding occurs prior to migration, even though I once observed a bachelor flock of two hundred on the Nicola Lake marsh, near Merritt, British Columbia, as late as 6 November 2000.

Evidently the timing of first arrivals and peak autumn movements has not advanced during the latter half of the twentieth century, even though the Mackenzie Basin region has experienced the greatest warming in Canada in the last five decades, by as much as $1.5^{\circ} \mathrm{C}$ (Woo et al. 2007). However, the temperature increase has occurred only in winter; summer temperatures have shown no trend and freeze-up time has remained consistent (Duguay et al. 2005; Jefferies 2005). Thus, although ice duration has decreased over the last two centuries due to global warming, it is not due to later freeze-up but rather to earlier break-up. If a slight change in air temperature is sufficient to shift freeze-up dates by several weeks, one would expect that the peaks of Bufflehead migration would shift accordingly over decades. In fact the timing of the first influx does not appear to have changed in decades, falling within the average range of freeze-up time in Back Bay, Yellowknife (Menard et. al. 2002).

Menard et al. (2002) found that computer simulations of freeze-up dates were later by six days than actual observations. Undoubtedly, the timing and volume of Bufflehead flights are a more precise and inte- 
TABLE 1. First arrivals of Buffleheads on Roberts Bay, 1996-2005.

\begin{tabular}{|c|c|c|c|c|c|}
\hline Year & October & Julian day & Time & Total Number & Number of males \\
\hline 1996 & 17 & 291 & 09:00 & 6 & 2 \\
\hline 1997 & 13 & 286 & - & 8 & 2 \\
\hline 1998 & 16 & 289 & $14: 00$ & 2 & 2 \\
\hline 1999 & 15 & 288 & $12: 00$ & 4 & 1 \\
\hline 2000 & 12 & 286 & $11: 15$ & 1 & 0 \\
\hline 2001 & 15 & 288 & $08: 30$ & 1 & 1 \\
\hline 2002 & 13 & 286 & 09:00 & 3 & 1 \\
\hline 2003 & 15 & 288 & $08: 35$ & 7 & 3 \\
\hline 2004 & 19 & 293 & $08: 30$ & 5 & 2 \\
\hline 2005 & 15 & 288 & $08: 40$ & 1 & 0 \\
\hline \multicolumn{2}{|c|}{ Average \pm S. D. } & \multicolumn{2}{|c|}{$288.3 \pm 2.3$} & $3.1 \pm 1.5$ & $1.4 \pm 0.9$ \\
\hline
\end{tabular}

grative measure of freeze-up. The narrow variation found in this study suggests that monitoring of their numbers from certain localities, in conjunction with shore-based observations of freeze-up, would (a) help validate one-dimensional thermodynamic models, (b) add a light-sensitive ecological indicator, representing the advance of the $0^{\circ} \mathrm{C}$ isotherm, and (c) provide a more meaningful index of climate change across the western boreal region, at minimal cost. This could be achieved through citizen participation.

Long dismissed as amateur natural history, phenology has become popular again with the rise of citizen participation in environmental and ecological monitoring programs. More and more citizens, concerned about the impacts of global warming, are participating in "earth-watch" programs, creating phenological statistics by which to gauge environmental change. Haupt (2006) argued that lay people need to reclaim natural history and become involved in their own biological education. What better way, she suggested, than to keep a diary "phenological awareness immerses us in the rhythmic dimensions of the natural world ... we become engaged, watchful, and increasingly resident."

But a phenological notebook has little meaning unless observations are carried on diligently beyond the typical limited time frame of biological studies; only then can meaningful statistics be generated. Most phenological studies naturally emphasize the early arrival of spring migrants as indicative of a climate change in the northern hemisphere (Cotton 2003); however, the accumulated energy budget of boreal aquatic ecosystems is determined by the switch-off date, tripped by "old Jack Frost," setting the Bufflehead in motion. In a climate of change, the punctual Bufflehead is a comforting constant. Bucephala exclararet nos.

\section{Acknowledgments}

Dedicated to Valerie. I'm honoured to have received the expert advice of the author of Buffleheads, Tony Erskine, and of the father of prairie ornithology, C. Stuart Houston.
Document Cited (marked * in text)

Environment Canada. 2006. Climate data online. www. climate.weatheroffice.ec.gc.ca/prods_servs/index_e.html.

\section{Literature Cited}

Bellrose, F. C. 1976. Ducks, geese and swans of North America. Second edition. Stackpole Books, Harrisburg, Pennsylvania. 544 pages.

Cotton, P. 2003. Avian migration phenology and global climate change. Proceedings of the National Academy of Sciences 100: 12219-12222.

Dawe, N. K. 1982. Use of Shoal Harbour Bird Sanctuary by migratory birds. Report by Environment Canada, Canadian Wildlife Service, Qualicum Beach, British Columbia. 13 pages, appendices 1-7.

Duguay, C. R., T. D. Prowse, B. R. Bonsai, R. D. Brown, M. P. Lacroix, and P. Menard. 2005. Recent trends in Canadian lake ice cover. Hydrological Processes 20: 781-801.

Erskine, A. J. 1972. Buffleheads. Canadian Wildlife Service Monograph Series 4. Information Canada, Ottawa. 240 pages.

Evans, M. R., D. B. Lank, W. S. Boyd, and F. Cooke. 2002. A comparison of the characteristics and fate of Barrow's Goldeneye and Bufflehead nests in nest boxes and natural cavities. Condor 104: 610-619.

Finley, J. K. 2001. The great Bufflehead crash, 1940. Blue Jay 58: 161-167.

Finley, J. K. 2007. Offshore flight of Buffleheads (Bucephala albeola) after twilight in winter: an anti-predation tactic? Canadian Field-Naturalist 121: 375-378.

Gauthier, G. 1993. Bufflehead, Bucephala albeola. The birds of North America (67). 24 pages. Edited by A. Poole and F. Gill, The Academy of Natural Sciences of Philadelphia.

Haupt, L. L. 2006. Pilgrim on the Great Bird Continent. The importance of everything and other lessons from Darwin's lost notebooks. Little, Brown and Co., New York. 276 pages

Jefferies, M.O. 2005. Lake ice growth and decay in central Alaska, USA: observations and computer simulations compared. Annals of Glaciology 40: 1-5

Menard, P, C. R. Duguay, G. M. Flato, and W. R. Rouse. 2002. Simulation of ice phenology on a large lake in the Mackenzie River Basin (1960-2000). 59 ${ }^{\text {th }}$ Eastern Snow Conference, Stowe, Vermont USA. 12 pages.

Swallow, H. S. 1941. Rain of ducks at Foam Lake, Saskatchewan. Canadian Field-Naturalist 55: 130. 
Welty, J. C. 1975. The life of birds. Second edition. W. B. Saunders Co., Philadelphia. 623 pages.

Woo, M., P. Modeste, L. Martz, J. Blondin, B. Kochtubajda, D. Tutcho, J. Gyakum, A. Takazo, C. Spence, J.

Tutcho, P. Di Cenzo, G. Kenney, J. Stone, I. Neyelle, G. Baptiste, M. Modeste, B. Kenny, and W. Modeste.
2007. Science meets traditional knowledge: water and climate in the Sahtu (Great Bear Lake) region, Northwest Territories, Canada. Arctic 60: 37-46.

Received 20 April 2007

Accepted 25 March 2008 